\title{
The Study on the Effect of Zikir Protocols Training towards Performance of Heart Rate Variability (HRV) and Academic Achievement among Secondary Schools Students
}

\author{
Muhammad Nubli Abdul Wahab \\ Centre for Modern Language \& Human Sciences, \\ University Malaysia Pahang, \\ Lebuhraya Tun Razak, 26300, Gambang \\ Pahang, Malaysia
}

\begin{abstract}
Zikir has been known to have a direct impact on the individual. Zikir is able to help individuals make behavioural changes. Zikir is known to have an impact on the mind, emotions and behaviour. An investigation was conducted to identify the extent implemented zikir able to help individuals make changes themselves. Clinical studies carried out by taking 219 respondents among secondary school students who were involved in the disciplinary problems. Zikir intervention enables us to make changes ourselves using the technique of "Heart Rate Variability" (HRV). Students were given technical chanting slowly, loudly, and several techniques of zikir such as tahlil, istighfar and salawat. Conversion emWave@tm had recorded using a look at how the students were able to make changes themselves. The study found that students who successfully completed the zikir training able to make changes themselves and result in academic performance improvement. Students had successfully made a change to the change score "HRV Coherence" of the VLF spectrum of LF and HF spectrum conditions. This technique can be used in schools to improve the effectiveness of prevention of disciplinary problems therefore enabling education programs to be implemented.
\end{abstract}

\section{Keywords}

Zikir, Heart Rate Variability, HRV, biofeedback, students, academic, discipline

\section{INTRODUCTION}

Emotions have a very close relationship with behavior. Individuals who are able to control emotions will be able to better control the activity. Calm the mind, emotions under control will lead to more organized activities and controlled behavior. [1] A study conducted shows that people who are able to control emotions have better athletic performance [2]. The same holds if associated with students. Individuals who are able to control emotions will be able to control their behavior better and on beneficial ways. On the other hand, individuals who are unable to control emotions will be difficult to perform activities well. They are easily worried, restless and angry while doing activities. This provokes them to create disciplinary problems at school. Generally experimental work on psychophysiology stimulus variation and emotional, cognitive or behavioral response changes depending on the use of biofeedback approach [3], [4]

Heart rate Variability (HRV) is termed as a joint time/frequency study of the beat-to-beat responses in the heart rate [1]. HRV biofeedback aims to control the oscillation variability in heart rate [5]. states that there are three related

\author{
Aiman Atta \\ Centre for Modern Language \& Human Sciences \\ University Malaysia Pahang \\ Lebuhraya Tun Razak, 26300, Gambang, Pahang, \\ Malaysia
}

types of spectrum: the VLF (very low frequency) frequency less than 0:03 Hz, LF (low frequency), with a frequency range of 0:03 and $0.15 \mathrm{~Hz}$, and $\mathrm{HF}$ (high frequency) between 0.18 and frequency range $0.4 \mathrm{~Hz}$ [6]. HRV Biofeedback show potential in increasing performance and he also states many employees perform their cognitive function below the level of the actual cognitive ability caused by fatigue, work stress and boredom[7]. Studies have revealed that higher HRV associated with creativity, psychological flexibility and capacity to adapt faster response in cognitive, affective and physiological emphasis [8] whereas low HRV is associated with anxiety, depression and different cardiovascular. Health factors can also cause an increase in certain heart rhythms, including emotional, anxious thinking, breathing, pressure in the arteries and other behavioral and physiological changes [8].

Zikir in etymology is derived from the Arabic word 'dzakara' which means remembering, in terminology means a practice speech through recitations and remembrance of Allah. Zikir is the physical and mental activities that form acceleration from reflection, attitude, and behavior until the process of life that reminds us of God [9]. Zikir is able to calm the mind and plays a role in determining a person's character. Zikir is the best traditions of worship and most pleasing to Allah, the lightest and most easily done by not having certain conditions and rules. It can be done at any time, any place and at any state [10]. Zikir has psychological and spiritual benefits. Psychologically, it gives a sense of spiritual comfort and it gives a sense of being closer to God [11]. When a person is more likely to do good deeds such as reciting zikir and remembering Allah, Allah will spare him from committing sins therefore helps forming a good personality within that individual.

Recent researches [12] have publicized the consequence of HRV biofeedback to the development of some cognitive functions in both simulated and real industrial operators. Patients with coronary heart disease (CHD) have psychological stress exhibit decreased vagal control of heart rate (HR), as measured by spectral analysis of HR variability (HRV) [13]. Student shows the better performance which increase academic achievement after doing zikir intervention. [14]

\subsection{Biofeedback Protocol}

In making students' disciplinary behavior change, students are taught on methods to control emotions and strengthen it. Methods or protocols focus on breathing that uniform, focusing on mind and physical control. Through this protocol, students were asked to control on focusing their mind, heart 
rate and respiratory control. Controlling of these components has a direct relationship with emotional performance. Individuals, who are able to control emotions, have a direct effect on pulse and vice versa. Protocols which are taught to the participants are in the form of breathing exercises and focusing on the mind.

Students are required to do the work out 3 times a week for 20 minutes to familiarize themselves with the methods of controlling the mind, controlling the pulse and respiration. Students are required to do the training for 4 weeks. During this training period, students are required to attend the biofeedback training room and undergo the required training.

This monitoring method is also implemented to allow students to self-change naturally according to the demands of themselves to change and to be a better student. Students are not required to inform their friends that they are involved in the recovery program. This situation is designed to enable students to apply themselves in understanding the concept of changing naturally in the learning environment and local partners alike. This program does not separate students from their classmates, but they are allowed to hang out with their friends in common, but with self-control avoiding the bad things and focus more on behavior changes. This process is implemented to build the inner strength on how to deal with peer pressure and make the selection that is good or otherwise at the expiration of the training session.

\subsection{Training Session}

The training session had been conducted for both the counselor and the student. The training sessions were firstly introduced briefly to the counselor by the instructor of the program. The training sessions for the counselor involve in 4 session of training as below;

\subsection{Biofeedback Principles Course and Intervention of Discipline Problem (Theoretical and Practical).}

This session was conducted in the training Centre where all the biofeedback devices were installed on for each school's computer. Then, the set up devices and protocol were altogether ready to use by the counselor and the students.

\subsection{Advanced Course Biofeedback \& Student Discipline Problems Intervention Protocol;}

The advance training course was conducted in the training Centre with the same procedures as the first session using the computer that had been installed with the biofeedback devices. Throughout one month of practical training, the protocol was applied to the students in their respective school.

\subsection{Advance Course for Biofeedback Devices Technical Handling \& Advance Student Discipline Problems Intervention Protocol.}

This advance training was held in a selected school in order to help any difficulties in the configuration or handling of the devices and protocol by the counselors.

\subsection{Course Conclusion, Biofeedback Device Competency Test \& Achievement Report.}

The last session was held at one of the school to summarize and conclude the results. The competency test for the counselor is for identifies the capability of handling the biofeedback devices. The results obtained had been analyzed and compared with the academic achievement of the students.

The trainings for student were conducted in a quiet room reserved for the participants of the study in a school in Maran, Pahang. Malaysia. The condition of the room was made to be really conducive environment with less or no emotion distraction. Each participant attends a training session at the same time and same day every week Counselor are taught to use the protocol and use it together with the students. Training is given to individual participant. After that is a brief description of the proposed training intervention protocol by Lehrer. In the first session participants were introduced to the experimental group biofeedback equipment, training methods and protocols proposed by [15]. Each participant must breathe in a relaxed state of mind and the resonance with swing heart rate (HRV) they are measured. The training sessions mostly focused on the application of the zikir by the students for every activity done with the HRV results obtained.

\section{METHOD}

In this study, the method of the intervention training for a group of students is done is done in 4 months' time. The intervention group for the biofeedback training chanting received six training sessions which implemented based on previous study that can improve performance result [7]. The purpose of this study is to measure the coherence in psychophysiological that is "a state of sustained positive emotion, a high degree of mental and emotional stability, constructive integration of the cognitive and emotional systems and increased synchronization and harmony between cognitive, emotional and physiological systems" [16]. The effect of implementation of zikir recitation in the training session had been measured in the study conducted.

\subsection{Participants}

The sampling is done by selecting students from five secondary schools. These students who have been identified are those who have low academic achievements and were always involved in the violation of discipline in schools. A total of 219 students were selected as a sample and they are going through a rehabilitation program behavior using chanting and biofeedback methods.

\subsection{Procedures}

The students were encouraged to relax and sit on a chair calmly. After properly connecting the ear sensor, a monitor viewing the heart rhythm pattern of VLF, LF or HF. Their heartbeat rate would be measured and recorded using the emWave desktop Software Kit devices to detect their emotion through their heart rate rhythm pattern.

During the first 10 minutes session of the training, the students were made sure to be in a good physiological condition. All of the records and details of academic and behavioral of the students before, during and after the training should be recorded properly for further comparison.

In the first procedure, the baseline was fixed at 5 minutes. While they are in a relax situation, which is in a normal situation, their heart rate was recorded for 5 minutes and stopped. Then for the second baseline, the students were instructed to take ablution and do the solah for two rakaat. The next reading was taken after the student finished solah and the result from HRV results for both reading was compared.

Later, they were asked to recite zikir "Laila ha illallah "by tongue clearly in gentle voice solemnly for five minutes. 
Continuously with the same procedures, they were asked to recite zikir "Laila ha illallah" in their heart for 5 minutes. The results for both training of zikir can be compared by the score obtained.

The students then were assisted to breathe with the uniform and organized way with coherent coach techniques to correct their coherent psychophysiological while still reciting the zikir. The next 5 minutes session is a game session where the student will able to demonstrate the control of the consistency in the breathing pattern.

Finally, the training results done by students were linked and being correlated with the academic performance by the students. The trainings were repeated for about few days later with about 20-30 minutes for each training session.

The differences of this project with other projects before, is where this project provided training to counselors using the protocol of remembrance and counselors to use with students in trouble at school. In other training procedures, training sessions run by coaches who have undergone training. In contrast, in this study, the training was given to teachers and their training sessions with students. The goal would be to enable teachers to use the protocol to improve the performance of HRV remembrance and allow students to make changes in the behavior of the protocol developed.

\section{RESULTS AND DISCUSSION}

The results present the HRV performance of participants, the effect of the protocol toward the behavioral changes and the relation to the academic performance of the participants. The effect of the zikir throughout the training is being discovered to find the correlation for in the HRV performances. The results are analyzed to take the most effective result for the biofeedback intervention training to those selected participants. Those discussions on the results were explained as below in;

\subsection{HRV Performances of the Participants}

The results from the data taken shows that most of the student did show great improvement of the HRV reading after several training compared to the reading at the beginning of the session. The observation of HRV results can be clearly seen by the graph produced from the data recorded by the emWave@tm devices.

The observation of the HRV performances is measured by the different motion of heart rhythm pattern of VLF, LF or HF. The successful participant is expected to get the higher for the HF amplitude value after the series of training had been undergone than the pre-result score of HF amplitude. Most of the participant that had been undergone the training previously had been significantly resulted in a better HRV amplitude than before. Maximal performance control over the

HRV can be obtained after series of approximately four sessions of training [12]. The students that have the good result on the HF score meaning that they are capable of control themselves to be in a relaxing state. Thus they can manage their mind by controlling the pattern of the breathing that will be consequently resulting in the slow heartbeat and higher HRV performances.

In this study, the results recorded from a number of students $(n=219)$ is directly as the results expected should be. The pre and post of the training had been tabulated and summarized. The value of the HRV score shows that better performance had been exhibited by the students after the training. Figure 1 below show the summary of comparison between the different rhythms pattern of the heart. The VLF, LF and HF pattern differentiate increasing or decreasing that was recorded by the emWave ${ }^{\circledR \mathrm{tm}}$ devices. The summary of results can be seen as below:

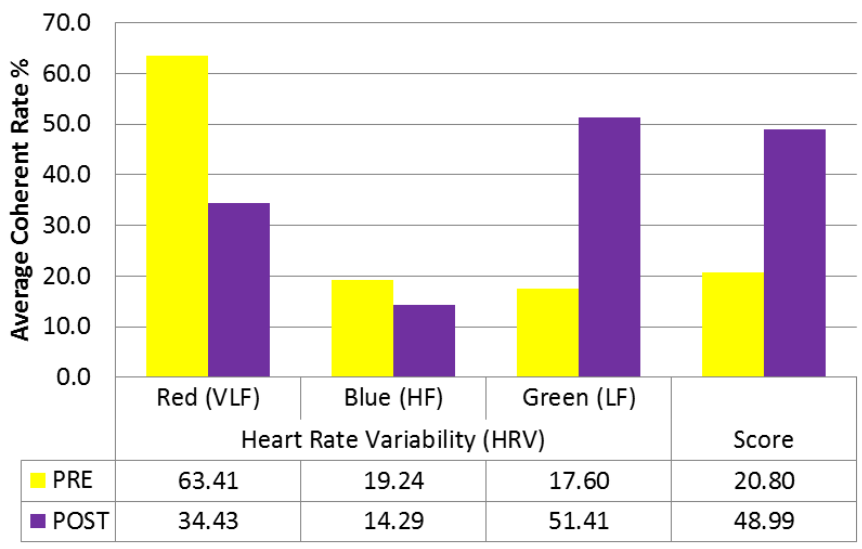

Fig.1 Comparison HRV responses for students; Pre and Post

From the results of the average HRV performance analysis, the early conclusion can be made that the effect of the zikir chanting had been significantly effect on the improved performance of the HRV of participants. Throughout the rehabilitation training, the increased performance supposed to be seen by the participants as they had undergone and learnt how to manage themselves in a better way. As discussed by [17], self-regulation and self-control skills can be acquired and used to correct of their states toward the optimal performance. The initial training result during the baseline session is becoming the benchmark with the last training that had been going through in order to identify the effectiveness to know the zikir effect throughout the rehabilitation process. The VLF frequency is reduced in the post-result similarly to the HF frequency result. The focus is on how the red and blue or VLF and HF frequency will be lowered while increasing the LF frequency coherent rate. In this comparison result figure, we can clearly see that the green (LF) is higher in the post-result than the initial score. This gives a support evidence of the positive effect of the training protocol used. Table 1 show the comparison of the mean of the coherence of LF is increasing from $17.4 \%$ to $50.7 \%$ which is consider is high increment although similar study had shown better improvement in the coherence score up to $86.2 \%$ [18].

Table 1 Comparison of Mean Values of Coherence Rate

\begin{tabular}{|c|c|c|}
\hline Measures HRV & Mean Values (\%) & Standard Deviation (\%) \\
\hline Pre & 17.4 & 23.6 \\
\hline Post & 50.7 & 34.9 \\
\hline
\end{tabular}

\subsection{Academic Performances Analysis}

The performances of the students had been recorded in a report to be analyzed. The result summarized in Figure 2 as an overall grade average improvement of the student. The analysis shows that the performance of the students did increase by $34 \%$ for the academic results performance. The results were taken by the school teachers from the pre and post-results of from the academic evaluation in the school. Thus this signifies the successful in the zikir intervention procedure for the students. 


\subsection{Discipline rate decrement}

The students did show a significance change in behavior after undergoing complete series of the training. The discipline problem rate of the students decreased throughout the process of intervention. The results observed before the training and after the training completed by the students. From the observation, the rate of disciplinary problems amongst the student did show the declined rate based on the behavioral changes of the students. However this method of observation did need a continuous remark from the counselors and takes time to be completed.

The review for the discipline rate decrement had been illustrate in the Figure 2 of the declining of discipline problems together with the improved morality of $60 \%$ and $55 \%$ respectively from an overall average for all of the participants. Thus the outcomes from the study did succeed by the implementation of zikir protocol together with right respiratory control to the students may improve students bad symptom or behavior.

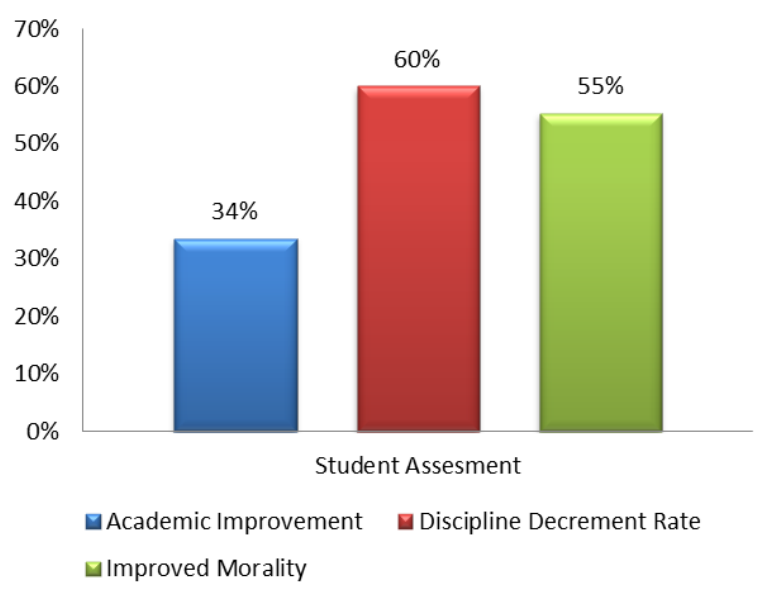

Fig.2 Summaries of the Student Assessment

The students that undergone this training program will be able to control themselves from the bad things as they can focus more on building the inner strength to deal the surrounding and peer-pressure and thus can make the selection that is good or otherwise. The remembrance of Allah in throughout the sessions is implemented so that the students feel that they should not do bad things in their everyday life.

\section{CONCLUSION}

Overall, a study found that a combination of modules biofeedback and zikir chanting together with the correct breathing exercises can be used to help student with bad behavior to make changes in the attitudes. Thus the effect of the modules had been significantly found to be also effective in the academic improvement of the students.

The program is intended to make student with disciplinary problems to be better in term of their self-control, and provide a behavior recovery in turn to help reducing the student involvement in the bad symptom. The process implementation from the module protocol intervention using zikir is complete enough to be rehabilitation training for recovery process for those who have low academic performances and involved with the violation of discipline in the school. Duration of the academic performances that can be made is highly dependent on the extent to which force themselves to maintain new emotion and attitudes. However the time for the analysis for the academic progress in the duration right after the training may not show a great differences because with time consume, the student should be noticed for their improvements. The effects of implementation of zikir in biofeedback intervention protocol need serious attention from researchers so that people could understand the importance of zikir in everyday activities in their life.

\section{ACKNOWLEDGEMENT}

This work has been supported under the research grant No. RDU1103101, Universiti Malaysia Pahang, Malaysia.

\section{REFERENCES:}

[1] B. M. Appelhans and L. J. Luecken, Heart Rate Variability As An Index Of Regulated Emotional Responding, Review of General Psychology, Vol.10, 2006, pp. 229-240.

[2] D. Hammond, Neurofeedback for the Enhancement of Athletic Performance and Physical Balance, The Journal of the American Board of Sport Psychology, Vol.1, 2007, pp. 1-9.

[3] W. C. Drevets, Neuroimaging and Neuropathological Studies of Depression: Implications for the CognitiveEmotional Features of Mood Disorders, Current Opinion in Neurobiology, Vol.11, 2001, pp. 240-249.

[4] G. Bush, P. Luu, and M. Posner, Cognitive and Emotional Influences in Anterior Cingulate Cortex., Trends in Cognitive Sciences, Vol.4, 2000, pp. 215-222.

[5] P. M. Lehrer, E. Vaschillo, B. Vaschillo, S.-E. Lu, D. L. Eckberg, R. Edelberg, W. J. Shih, Y. Lin, T. A. Kuusela, K. U. O. Tahvanainen, and R. M. Hamer, Heart Rate Variability Biofeedback increases Baroreflex Gain and Peak Expiratory Flow, Psychosomatic Medicine, Vol.65, No.5, 2003, pp. 796-805.

[6] Task Force of the European Society of Cardiology and the North American Society of Pacing and Electrophysiology, Heart rate variability. Standards of Measurement, Physiological Interpretation, and Clinical Use, European Heart Journal, Vol.17, No.3, 1996, pp. 354-381.

[7] A. Sutarto and A. Nubli, The Use Biofeedback for Enhancing Cognitive Performance in Industrial Training Setting, National Conference on Skilll and Compentencies in Education (NSCCE) USM Penang, 2008.

[8] L. Lagos, E. Vaschillo, B. Vaschillo, P. Lehrer, M. Bates, and R. Pandina, Heart Rate Variability Biofeedback as a Strategy for Dealing with Competitive Anxiety: A Case Study, Biofeedback, Vol.36, 2008, pp. $109-115$.

[9] S. M. Amin and H. Al-Fandi, Energi Dzikir. Jakarta: Penerbit Amzah, 2008.

[10] A. Y. Saleh, Berzikir untuk Kesehatan Saraf. Jakarta: Penerbit Zaman, 2010

[11] I. Khan, Dimensi Spiritual Psikologi. Pustaka Hidayah, Bandung, 2000

[12] A. P. Sutarto, M. N. A. Wahab, and N. M. Zin, Heart Rate Variability (HRV) biofeedback: A New Training Approach for Operator's Performance Enhancement, Journal of Industrial Engineering and Management, Vol.3, No.1, 2010, pp. 176-198. 
[13] R. P. Nolan, M. V. Kamath, J. S. Floras, J. Stanley, C. Pang, P. Picton, and Q. R. Young, Heart Rate Variability Biofeedback as a Behavioral Neurocardiac Intervention to Enhance Vagal Heart Rate Control, American Heart Journal, Vol.149, No.6, 2005.

[14] S. M. Rozali, M. Nubli, and A. Wahab, A Pilot Study of the Effect of Zikir on the Performance Psychology Using Heart Rate Variability (HRV), 2013, pp. 2-5.

[15] P. M. Lehrer, E. Vaschillo, and B. Vaschillo, Resonant Frequency Biofeedback Training to Increase Cardiac Variability: Rationale and Manual for Training, Applied Psychophysiology and Biofeedback, Vol.25, No.3, 2000, pp. 177-191.
[16] R. McCraty, Science of the Heart. Exploring the Role of the Heart in Human Performance. 2001, pp. 1-72.

[17] N. M. Schwartz and M. S. Schwartz, Definitions of Biofeedback and Applied Psychophysiology, in Biofeedback A Practitioners Guide 3rd ed, 2003, pp. 2739 .

[18] S. M. Rozali, M. Nubli, A. Wahab, and Z. Mardiyyah, The Study of Heart Rate Variability (HRV) Biofeedback Through Zikir (Islamic Recitation) of High School Students, Journal of Engineering and Technology, Vol.5, No.1, 2014 